\title{
KRITIK SOSIAL DAN NILAI PENDIDIKAN KARAKTER DALAM NASKAH DRAMA THE DUKUN DAN RELEVANSINYA DENGAN PEMBELAJARAN SASTRA DI SEKOLAH MENENGAH ATAS
}

\author{
Wahid Ibnu Nugroho, Sarwiji Suwandi, Sri Hastuti \\ Universitas Sebelas Maret \\ Email: wahidibnunugroho@student.uns.ac.id
}

\begin{abstract}
Abstrak: Penelitian ini bertujuan untuk mendiskripsikan kritik sosial; nilai pendidikan karakter dalam naskah drama The Dukun karya Dukut Wahyu Nugroho, dan relevansinya dengan pembelajaran sastra di SMA. Sampel penelitian ini menggunakan teknik sampel purposive sampling, yaitu pemilihan sampel disesuaikan dengan masalah, kebutuhan, dan kemantapan peneliti dalam memperoleh data. Sumber berupa naskah drama The Dukun karya Dukut Wahyu Nugroho dan informan, kemudian pengumpulan data dalam penelitian ini diperoleh melalui kajian dokumen dan wawancara. Uji Validaitas data penelitian ini menggunakan trianggulasi teori dan trianggulasi sumber. Analisis data penelitian ini menggunakan teknik analisis interaktif yang terdiri dari pengumpulan data, reduksi data, penyajian data, dan penarikan kesimpulan. Hasil penelitian ini menyimpulkan bahwa naskah drama The Dukun di samping alurnya yang ringan dan dapat dipentaskan dalam pembelajaran SMA juga memberikan pesan moral yang mendalam bagi pembacanya. Pengaluran cerita yang runtut dapat dijadikan objek penelitian untuk menambah wawasan mengenai sosiologi sastra sehingga dapat diimplementasikan secara langsung kedalam pembelajaran Bahasa Indonesia di SMA dengan memperhatikan SK/KD yang digunakan.
\end{abstract}

Kata Kunci: kritik sosial, nilai pendidikan karakter, naskah drama, pembelajaran sastra

\section{SOCIAL CRITICISM AND CHARACTER EDUCATION VALUE IN “THE DUKUN" PLAY SCRIPT AND ITS RELEVANCE WITH LITERATURE LEARNING IN SENIOR HIGH SCHOOL}

\begin{abstract}
This research aims to describe social criticism; the value of character building in drama script "the dukun" by Dukut Wahyu Nugroho, and the relevance of drama script "the dukun" by Dukut Wahyu Nugroho as literary teaching material in the senior high school. The sampling technique used is purposive for the sample is chosen based on certain purpose in order to reach the objective of this research. The source of data is drama script "the dukun" by dukut wahyu nugroho and informant, therefore the data are collected by document review and interview. The test validity of the research data used triangulation of theory and triangulation of source. The analysis of data was done by interactive analysis which is consisting of data collection, data reduction, data presentation, and conclusion. The result of this research describes that the drama script "the dukun" besides has a simple plot and can be shown in senior high school learning, also gives a deep moral message to the reader. Story plotting that coherent can be used as a research object to add insight of the literature sociology, so can be implemented in learning Bahasa Indonesia in senior high school and keep mind to the SK/KD which is used.
\end{abstract}

Keyword: social criticism, character building value, drama script, literary learning

\section{PENDAHULUAN}

Sastra senantiasa memliki keterkaitan dengan peristiwa-peristiwa yang terjadi di masyarakat, khususnya terkait permasalahan sosial. Dalam hubungannya dengan hal tersebut, sastra dengan keluasannya dalam menyampaikan pesan kerap kali mengkritisi permasalahan sosial secara pedas namun dengan cara penyampainnya yang estetis, simbolik, tetap beretika, namun mengena. Ratna (2008: 60) berpendapat, sesuai dengan hakikatnya, sebagai sumber estetika dan etika, karya sastra tidak bisa digunakan 
secara langsung. Oleh karena itulah, model pendekatannya adalah pemahaman dengan harapan akan terjadi perubahan perilaku masyarakat. Apabila manusia sudah tidak mungkin mencari kebenaran melalui logika, ilmu pengetahuan, bahkan agama, maka hal ini diharapkan dapat terjadi dalam karya sastra.

Karya sastra yang sesuai dengan pendapat tersebut adalah naskah drama. Di dalam naskah drama terdapat nilai-nilai kehidupan yang bisa sebagai representasi kehidupan sosial. Waluyo (2006: 2) berpendapat bahwa naskah drama merupakan salah satu genre sastra yang disejajarkan dengan puisi dan prosa serta dapat diberi batasan sebagai salah satu jenis karya sastra yang ditulis dalam bentuk dialog yang didasarkan atas konflik batin dan mempunyai kemungkinan dipentaskan. Dialoh memang telah menjadi ciri khas drama atau naskah drama. Dialog mencerminkan pembicaraan dalam kehidupan sehari-hari dan bersumber pada pembicaraan dalam kehidupan kehidupan sehari-hari. Karya-karya naskah drama telah banyak mengangkat beragam tema, mulai dari sosial, religi, politik, percintaan maupun lingkungan.

Berbicaratentangkritiksosialdan

percintaan, salahsatukaryasastra yang mengangkat kedua tema besar tersebut adalah naskahThe Dukun karya Dukut Wahyu Nugroho. Naskah drama The Dukun ini memiliki cerita yang terdapat beberapa pesan moral yang akan di sampaikan oleh Dukut Wahyu Nugroho. Pesan moral tersebut dapat dikaji dengan tinjauan sosiologi sastra yang merupakan pengkajian tentang kritik sosial yang terjadi di dalam kehidupan.

Naskah drama ini juga dipilih sebagai bahan ajar, khususnya pada jenjang pendidikan SMA. Dalam Kurikulum 2013, kegiatan apresiasi drama dilaksanakan di kelas XI, dengan dua kompetensi dasar yang harus dicapai siswa, yaitu 1) Memahami struktur dan kaidah teks film/drama, baik secara lisan maupun tulisan 2) Menginterpretasi makna teks film/drama, baik secara lisan maupun tulisan.Naskah drama tersebut dapat dipilih karena selain terbukti kerap dipilih oleh para pelajar dalam pementasan drama, naskah ini juga memiliki nilai-nilai pendidikan karakter yang kaya, tapi tetap mudah dipahami dikarenakan bergenre komedi. Hal inilah yang menjadi pertimbangan peneliti memilih naskah tersebut sebagai bahan ajar apresiasi drama di SMA.

\section{METODE PENELITIAN}

Penelitian ini menggunakan metode kualitatif dengan rancangan penelitian deskriptif kualitatif. Sutopo (2002: 11)menyatakan bahwa metode deskriptif kualitatif mengarah pada pendiskripsian secara rinci dan mendalam mengenai potret kondisi tentang apa yang sebenarnya terjadi menurut apa adanya di lapangan studinya.

Metode deskriptif juga dapat diartikan sebagai prosedur pemecahan masalah dengan menggambarkan atau melukiskan keadaan subjek atau objek penelitian (seseorang, lembaga, masyarakat, dan seterusnya) pada saat ini berdasarkan fakta-fakta yang tampak atau sebagaimana adanya (Nawawi dalam Siswantoro, 2010: 56).

Pendekatan sosiologi sastra pada dasarnya mengaitkan penciptaan karya sastra, keberadaan karya sastra, serta peran karya sastra dengan realitas sosial masyarakat terhadap naskah drama The Dukun karya Dukut Wahyu Nugroho . Nilai-nilai pendidikan karakter pada dasarnya mengkaji tentang nilai pendidikan yang dapat diambil dalam naskah drama The Dukun karya Dukut Wahyu Nugroho sehingga dapat dijadikan bahan pembelajaran sastra di SMA.

Data atau informasi penting yang dikumpulkan dan dikaji dalam penelitian ini berupa data kualitatif. Data penelitian ini diperoleh melalui membaca naskah drama The Dukun karya Dukut Wahyu Nugroho. Informan dalam penelitian ini adalah Penulis, Dosen Sastra Fakultas 
Keguruan dan Ilmu Pendidikan Universitas Sebelas Maret, guru mata pelajaran bahasa Indonesia yang menerapkan Kurikulum Tingkat Satuan Pendidikan, guru mata pelajaran Bahasa Indonesia yang menerapkan Kurikulum 2013, peserta didik. Wawancara dengan dosen sastra FKIP, guru mata pelajaran Bahasa Indonesia dan peserta didik tersebut nantinya digunakan untuk mengetahui kesesuaian naskah drama The Dukun karya Dukut Wahyu Nugroho sebagai materi pembelajaran sastra di SMA.Mengacu pada tujuannya, penelitian ini mengambil sampel dengan menggunakan purposive sampling.

\section{HASIL DAN PEMBAHASAN}

\section{Latar Belakang Naskah DramaThe Dukun}

Dalam drama The Dukun alur yang terjadi dalam satu adegan ke adegan yang lain sangat berkaitan. Tidak ada bagian yang terpotong-potong maupun berloncatloncat. Semua adegan mengalami alur maju yang diceritakan dari pagi ketika pasangan suami istri Asdi dan Sumiyem bertengkar, datangnya Paidi dan Juminto mengakatan mencari dukun. Lalu bertemunya Paidi dan Juminto dengan Asdi yang disangka seorang dukun sakit. Kemudian ke adegan dimana Asdi yang disangka dukun harus mengobati Laras putrid dari Pak Sukoco dan ibu Sukoco.

Naskah drama The Dukun yang karya Dukut Wahyu Nugroho tercipta karena kecintaannya pada seni teater. Dukut membuat naskah drama ini karena keprihatinannya terhadap naskah baru di Indonesia yang masih dirasa kekurangan naskah-naskah baru. Dukut juga terinspirasi dengan Hanindawan dan Arifin C Noor ini, ingin mengembangkan teater dengan ilmu yang dimilikinya.

Dalam drama The Dukun, penokohan menjadi materi utama untuk menciptakan plot, karakter juga merupakan sumber action dan percakapan. Karena itu, karakter harus dibentuk agar cocok dengan kebutuhan plot, dan semua bagian dari setiap karakterisasi harus pas satu sama lain. Jika karakternya sama, tidak akan ada lakon. Inti dari sebuah naskah drama terletak pada hadirnya keinginan seorang tokoh dan ia berjuang keras untuk mencapainya.

Pada penelitian penokohan akan digambakan menjadi beberapa jenis antara lain tokoh protagonis, antagonis, tritagonis, dan peran pembantu. Dari semua jenis tokoh di atas merupakan rangkaian yang tidak dapat dipisahkan, karena antara tokoh yang satu dengan yang lainnya mempunyai tugas dan tanggung jawab penuh untuk mengemban tugas sesuai dengan tema atau tujuan dari cerita yang ingin dicapai.

Ada beberapa tokoh protagonis yaitu sebagai berikut ini. Asdi adalah tokoh utama dalam daram The Dukun ini. Asdi memiliki istri bernama Sumiyem yang cerewet. Kecerewetan Sumiyem membuat Asdi menjadi suami yang pemalas. Dia juga tidak mau bekerja keras untuk memenuhi hidup keluarganya. Namun, Asdi merupakan orang yang menjunjung tinggi nilai kesopanan antara suami dan istri. Dalam naskah drama The Dukun, Samiyem adalah istri Asdi. Samiyem mempunyai sikap yang cerewet terhadap suaminya. Selalu megeluh dengan keadaan yang membuat suaminya bermalasmalasan. Panji merupakan tokoh utama dalam naskah drama The Dukun ini. Karena dia adalah kekasih dari Laras yang sedang berpura-pura sakit untuk melawan ibuknya yang menjodohkan Laras dengan orang lain selain Panji.Laras adalah anak dari Pak Sukoco dan Bu Sukoco. Laras adalah kekasih Panji. Laras adalah orang yang mempunyai kepribadian menurut dengan apa kata orang tuanya. Namun untuk menutupi rasa sakit hatinya karena dia tidak mau untuk dijodohkan, maka ia berbohong dengan cara berpura-pura sakit tuli dan bisu.

Ada beberapa tokoh antagonis yaitu $\mathrm{Bu}$ Sukoco. Dia adalah tokoh antagonis dalam naskah drama the Dukun ini. Karena bu Sukoco adalah orang ang selalu berprasangka buruk terhadap orang lain. 
Selain itu, ada tokoh tritagonis sebagao berikut ini. Pak Sukoco adalah suami bu Sukoco dan ayah Laras. Pak Sukoco mempunyai sikap penyabar dan baik terhadap orang lain. Paidi adalah pembantu dari pak Sukoco dan bu Sukoco. Disini walupun Paidi tidak dijelaskan terlalu gamblang mengenai watak dan tokohnya, namun Paidi mempunyai sifat yang nurut terhadap majikannya. Paidi menjadi tokoh tritagonis karena dia mampu membuat jenaka dan membuat hidup pertunjukan drama tersebut. Sama seperti Paidi, Juminto juga tidak dijelaskan secara gambling watak dan penokohannya. Maka dari itu Juminto juga disebut dengan pemeran tritagonis yang mampu membawa drama lebih hidup. Karti adalah pembantu bu Sukoco dan pak Sukoco. Disini Karti juga sebagi pemeran pembantu yang dapat menghidupkan drama tersebut. Radiman adalah tetangga dari Asdi dan Sumiyem. Disini Radiman hanya berperan sebagai pemeran pembantu yang hany keluar disaat-saat tertentu saja. Dokter adalah orang yang membantu Laras pada saat pertunjukan. Dokter disini disebut sebagai peran pembantu karena hanya untuk menunjang pertunjukan bisa semakin hidup.

Tema utama dalam naskah drama the Dukun adalah percintaan. Dimana hubungan cinta antara Laras dan Panji yang harus terpisah lantaran orang tua Laras yang akan menjodohkan anaknya dengan orang kaya. Dengan bumbu kritik sosial tentang kehidupan rumah tangga Asdi dan Sumiyem drama ini juga bisa bertemakan tentang kemiskinan. Dimana keluarga Asdi dan istrinya hidup sangat miskin hingga menjual seluruh isi yang ada di rumah mereka. Kurangnya lapangan pekerjaan membuat Asdi selalu bertengkar dengan istrinya setiap pagi.

\section{Kritik Sosial yang Terdapat dalam} Naskah Drama The Dukun

Dalam naskah drama the Dukun

Terdapat kritik Sosial terhadap

Pemerintah, kritik terhadap Ekonomi, dan kritik terhadap Hak Asasi Manusia. Kritik terhadap pemerintah ditunjukan dengan pernyataan Asdi bahwa tidak apa-apa hidup dengan asset keluarga sendiri daripada dari asset milik Negara yang dilakukan kebanyakan pejabat.

Kritik terhadap Ekonomi dalam naskah drama the Dukun, banyak sekali kritik ekonomi yang ditampilkan. Karena tingkat kemiskinan dari keluarga Asdi dan kekayaan keluarga pak Sukoco sangat berbeda.Asdi yang tidak punya pekerjaan selalu saja dimarahi oleh istrinya.

Berbeda dengan keluarga Pak Sukoco yang kaya. Pada naskah drama the Dukun digambarkan betapa rumah pak Sukoco mempunyai kamar tamu yang banyak barang-barang antiknya. Dalam dialog juga ada tokoh Karti yang dijadikan pembantu di rumah pak Sukoco. Dalam dialog diatas juga digambarkan betapa keluarga pak Sukoco dapat membayar seorang dokter untuk merawat anaknya. Kekayaan pak Sukoco juga bisa dilihat dari sifat dermawannya terhadap sesamanya. Ketika dia tahu bahwa Asdi bukanlah dukun, tapi Asdi tetap dibayar sesuai dengan perjanjian awalnya

Kritik terhadap HAM (Hak Asasi Manusia) dalam naskah drama the Dukun ini terdapat beberapa kritik HAM yang menjadi konflik utama. Kritik HAM itu adalah disaat anak tidak bisa menentukan pilihan hidupnya untuk menikah dengan orang yang di cintainya.

Kritik sosial yang sangat menonjol dalam naskah drama the Dukun adalah kritik terhadap HAM atau Hak Asasi Manusia. Dalam naskah drama ini, terdapat konflik yang sangat menonjol yang dialami oleh pelaku utamanya yaitu tidak disetujui berhubungan dengan orang yang dia cintai. Hal ini menunjukan pelanggaran HAM yang dilakukan oleh orang tua yaitu Pak Sukoco dan Ibu Sukoco yang melarang anaknya Laras untuk berhubungan dengan Panji kekasihnya.

Di samping kritik sosial mengenai Hak Asassi Manusia yang dialami oleh 
Panji dan Laras, terdapat kritik sosial materialistis yang berhubungan dengan aturan-aturan yang adat istiadat orang jawa. Aturan-aturan yang berlaku dalam naskah drama the Dukun adalah persoalan perbedaan status sosial. Laras anak dari $\mathrm{Bu}$ Sukoco dan Pak Sukoco merupakan anak orang kaya yang ingin menikah dengan Panji yang merupakan anak orang miskin. Karena ibu Sukoco masih memegang teguh tentang bebet, bibit, bobot dari calon suami Laras, bu Sukoco melarang hubungan Laras dan Panji. Dalam hal ini, stratifikasi sosial dipandang melalui kacamata harta dan strata kebangswanan, bukan lagi pada keteguhan, cinta, dan visi yang sama. Hal yang menimpa Panji mash sering dijumpai dalam masyarakat, strata sosial seringkali diukur dengan harta dan jabatan, miskin dan kaya tidak pantas untuk menjalin hubungan.

\section{Nilai Pendidikan Karakter}

Naskah drama the Dukun ini mengandung 11 nilai pendidikan karakter yaitu: (1) Religius, (2) Jujur, (3) Toleransi, (4) Kerja Keras, (5) Demokratis, (6) Cinta tanah Air, (7) Menghargai Prestasi, (8) Berkomunikatif, (9) Cinta Damai, (10) Peduli Sosial, (11) Tanggung Jawab.

Nilai Religius ditunjukan ketika Asdi menyuruh istrinya untuk berpuasa karena puasa adalah ajaran Agama. Namun pada kenyataan sebenarnya adalah Asdi menyuruh istrinya berpuasa karena tidak mempunyai bahan makanan untuk dimakan di hari besuk. Daripada mengeluh seharusnya memang harus berpuasa agar sesuai dengan ajaran agama yang dianut.

Nilai kejujuran sebenarnya tidak secara eksplisit terdapat dalam dialog naskah the Dukun ini. Namun dalam naskah drama the Dukun ini diceritakan bahwa Asdi berbohong menjadi seorang Dukun dan akhirnya ketahuan oleh pak Sukoco dan ibu Sukoco. Kemudian diceritakan dimana Laras yang harus berbohong kepada orang tuanya agar tidak jadi dinikahkan dengan laki-laki pilihan keluarganya. Walaupun tidak dituliskan secara eksplisit, namun dapat diambil kesimpulan bahwa jujur akan lebih baik daripada harus berbohong dan membuat orang lain kecewa karena sikap tidak jujur yang dilakukan.

Toleransi ditunjukan pada saat Laras yang mencintai Paidi namun dilarang oleh orang taunya. Kemudian akhirnya orang tua Laras sadar untuk kebahagiaan putrinya dan menoleransi perasaan yang dimiliki oleh anaknya tersebut.

Nilai kerja keras tidak ditunjukan dalam dialog naskha drama the Dukun, hanya saja dijelaskan bahwa Asdi tidak mau berusaha dan bekerja keras uintuk memenuhi kebutuhan keluarganya. Hal ini tidak sesuai dengan nilai kerja keras dalam pendidikan karakter. Namun, dalam diambil pembelajaran bahwa orang yang malas bekerja itu tidak dapat menghasilkan apa-apa.

Nilai demokratis ditunjukan dengan dialog bahwa ibu Sukoco atau ibunya Laras yang tidak bersikap demokratis. Ibu Sukoco masih membeda-bedakan tentang orang kaya dan orang miskin. Hal ini bisa dijadikan contoh untuk penggambaran nilai demokratis.

Nilai cinta tanah air ditunjukan dengan Asdi bangga apabila hidup dengan hasil kekayaan sendiri. Dalam dialog diatas Asdi menyindir para pejabat yang suka korupsi dan memakan hak milik rakyat. Hal ini sejalan dengan nilai cinta tanah air yaitu tentang kepedulian Asdi untuk mengkritik pejabat yang suka korupsi.

Nilai menghargai prestasi ditunjukan dengan dialog bu Sukoco yang menghina seorang dokter karena tidak bisa menyembuhkan anaknya. Hal ini tidak mengandung nilai menghargai prestasi. Namun bisa dijadikan sebuah contoh untuk penggambaran bagaimana menghargai prestasi sesorang.

Nilai komunikatif ditunjukan dengan percakapan dari Paidi dan Juminto dengan Sumiyem. Walaupun Paidi dan Juminto tidak kenal dengan Sumiyem, namun mereka melakukan komunikasi dengan 
baik untuk menanyakan rumah seorang dukun.

Nilai cinta damai ditunjukan dengan Radiman yang melerai perkelahian antara Asdi dan Sumiyem istrinya.

Nilai Peduli Sosial ditunjukan oleh pak Sukoco yang mau memberikan uang kepada Asdi yang jelas-jelas sudah menipu keluarga pak Sukoco dan Bu Sukoco.

Nilai tanggung jawab ditunjukan dengan Paidi dan Juminto dan melaksanakan tugas dari majikannya. Mereka senantiasa ingin segera melaksanakan tugas itu membawa seorang dukun untuk menyembuhkan ndoro putrid Laras.

\section{Relevansinya dalam Pembelajaran Apresiasi Sastra di SMA}

Implementasi dalam pembelajaran berdasarkan pada kegiatan yang terencana untuk mencapai suatu tujuan pembelajaran. Oleh karena itu, dalam implementasi guru perlu memahami konsep kurikulum dan silabus, serta mengembangkan RPP sebagai landasan perencanaan dalam aktivitas pembelajaran. Hal ini diperkuat dengan teori dari Usman (2002: 70) yang berpendapat bahwa implementasi bermuara pada aktivitas, aksi, tindakan, atau adanya mekanisme suatu sistem. Implementasi bukan sekedar aktivitas, tetapi suatu kegiatan yang terencana dan untuk mencapai tujuan kegiatan.

Naskah drama the Dukun ini merupakan salah satu drama yang menarik untuk dipentaskan dan dijadikan alternative materi aspresiasi sastra di SMA. Dalam silabus pembelajaran Bahasa Indonesia kelas XI SMA terdapat KD 4.2 yaitu 'Memproduksi teks film/drama yang koheren sesuai dengan karakteristik teks yang akan dibuat baik secara lisan mupun tulisan'. Sependapat dengan Samsi, dalam silabus tertuliskan bahwa materi pokok yang harus diajarkan oleh siswa mengenai: (1) Analisis bahasa teks naskah drama; (2) Menganalisis isi sesuai dengan struktur isi teks naskah drama; dan (3) Penyuntingan bahasa sesuai dengan: struktur kalimat, ejaan, dan tanda baca disesuaikan dengan ekspresi dan intosi dalam mempraktekan teks naskah drama.

Berdasarkan standar kompetensi dan kompetensi dasar mata pelajaran Bahasa Indonesia untuk SMA, Badan Standar Nasional Pendidikan (2006: 260) menyatakan bahwa pembelajaran Bahasa Indonesia diarahkan untuk meningkatkan kemampuan peserta didik untuk berkomunikasi dalam bahasa Indoensia dengan baik dan benar, baik secara lisan maupun tulis, serta menumbuhkan apresiasi terhadap hasil karya kesastraan manusia Indonesia. Dengan standar kompetensi mata pelajaran Bahasa Indonesia ini diharapkan: (1) Peserta didik dapat mengembangkan potensinya sesuai dengan kemampuan, kebutuhan, dan minatnya, serta dapat menumbuhkan penghargaan terhadap hasil karya kesastraan dan hasil intelektual bangsa sendiri; (2) guru dapat memusatkan perhatian kepada pengembangan kompetensi bahasa peserta didik dengan menyediakan berbagai kegiatan berbahasa dan sumber belajar; (3) guru lebih mandiri dan leluasa dalam menentukan bahan ajar kebahasaan dan kesastraan sesuai dengan kondisi lingkungan sekolah dan kemampuan peserta didiknya; (4) orang tua dan masyarakat secara aktif terlibat dalam pelaksanaan program berbahasa dan bersastra di sekolah; (5) sekolah dapat menyusun program pendidikan tentang kebahasaan dan kesastraan sesuaidengan kondisi dan kehasna daerah dengan tetap memperhatikan kepentingan nasional (BNSP, 2006: 260)

Naskah drama the Dukun selain dapat dijadikan bahan ajar, juga memiliki standar kelayakan sebagai materi ajar apresiasi sastra di SMA karena sesuai dengan potensi peserta didik dalam pembelajaran sastra. Dalam naskah drama the Dukun juga terdapat 11 macam pendidikan karakter yang tentunya dapat dijadikan materi ajar pembelajaran apresiasi sastra di SMA. 
Cerita dari naskah the Dukun dengan tema percintaan ini juga sangat ringan untuk dapat dijadikan referensi pembelajaran drama di SMA sesuai dengan Standart Kompetensi dan Kompetensi Dasar kurikulum 2013. Cerita yang ringan dan karakter yang kuat dalam menuliskan naskah drama the Dukun karya Dukut ini, mampu dijadikan bahan ajar di SMA. Relevansi sosiologi sastra dan pembelajaran terdapat dalam cerita dengan karakter yang jelas mampu di ekspresikan oleh siswa SMA sesuai dengan Standart Kompetensi dan Kompetensi Dasar kurikulum 2013.

\section{SIMPULAN}

Dalam drama The Dukun alur yang terjadi dalam satu adegan ke adegan yang lain sangat berkaitan. Tidak ada bagian yang terpotong-potong maupun berloncatloncat. Semua adegan mengalami alur maju.

Pada penelitian penokohan akan digambakan menjadi beberapa jenis antara lain tokoh protagonis, antagonis, tritagonis, dan peran pembantu. Tokoh itu antara lain: (1) Protagonis, yaitu: Asdi, Sumiyem, Panji, dan Laras; (2) Antagonis, yaitu: $\mathrm{Bu}$ Sukoco; (3) Tritagonis, yaitu: Pak Sukoco, Paidi, Juminto, Karti, Radiman, dan Dokter.

Ciri khas drama adalah naskah tersebut berupa dialog. Dalam menyusun dialog, pengarang harus memperhatikan pembicaraan tokoh. Ragam bahasa dalam dialog tokoh drama adalah bahasa lisan yang komunikatif dan bukan ragam bahasa tulis, maka diksi hendaknya dipilih sesuai dengan dramatic-action dari plot yang ada.

Latar naskah drama the Dukun sebagai berikut: (1) Latar tempat, yaitu: serambi rumah, tepi sungai, kamar tamu mewah, dan taman belakang rumah; (2) Latar waktu, yaitu pagi hari, dan sore hari

Tema utama dalam naskah drama the Dukun adalah percintaan. Dimana hubungan cinta antara Laras dan Panji yang harus terpisah lantaran orang tua
Laras yang akan menjodohkan anaknya dengan orang kaya.

The Dukun ditulis oleh Dukut Wahyu Nugraha adalah seorang pelatih drama Nglilir di SMA Negeri 1 Karanganyar. Dukut yang kuliah di jurusan teknik Informatika ini malah justru mencintai teater sejak berada di bangku SMA.

Kecintaan terhadap teater Indonesia membuatnya terinspirasi untuk membuat naskah drama yang di upload di bandarnaskah.blogspot.com. Naskah yang pernah di buatnya adalah Laras 1, Laras 2 dan the Dukun. The Dukun adalah karyanya yang terispirasi dari naskah Naskah Dokter Gadungan Karya Molliere dan Naskah Dukun-Dukunan karya Puthut Buchori.

Kritik sosial yang sangat menonjol dalam naskah drama the Dukun adalah kritik terhadap HAM atau Hak Asasi Manusia. Dalam naskah drama ini, terdapat konflik yang sangat menonjol yang dialami oleh pelaku utamanya yaitu tidak disetujui berhubungan dengan orang yang dia cintai. Hal ini menunjukan pelanggaran HAM yang dilakukan oleh orang tua yaitu Pak Sukoco dan Ibu Sukoco yang melarang anaknya Laras untuk berhubungan dengan Panji kekasihnya.

Naskah drama the Dukun ini mengandung 11 nilai pendidikan karakter yaitu: (1) Religius, (2) Jujur, (3) Toleransi, (4) Kerja Keras, (5) Demokratis, (6) Cinta tanah Air, (7) Menghargai Prestasi, (8) Berkomunikatif, (9) Cinta Damai, (10) Peduli Sosial, (11) Tanggung Jawab.

Berdasarkan analisis data dari informan prosedur pembelajaran Bahasa Indonesia kelas XI SMA terkait dengan pembelajaran apresiasi drama yang terdapat dalam silabus, maka dapat disimpulkan bahwa naskah drama the Dukun dapat dijadikan sebagai materi ajar apresiasi drama di SMA. Prosedur pembelajaran apresiasi drama bisa dilakukan dengan pembahasan mengenai struktur drama dan pengapresiasi drama. 
Guru mempunyai peranan penting dalam pemberian materi ajar. Dapat disimpulkan bahwa peran guru dalam menyaring materi

\section{REFERENSI}

Sutopo. H.B. (2002). Metodologi Penelitian Kualitatif. Surakarta: UNS Press.

Ratna, N.K. (2005). Sastra dan Cultural Studies. Yogyakarta: Pustaka Pelajar.

Siswantoro. (2010). Metode Penelitian Sastra Analisis Struktur Puisi. Yogyakarta: Pustaka Pelajar. ajar sangat diperlukan untuk menunjang kegiatan belajar yang tidak membosankan.

Waluyo, H.J. \& Wardani, N.E. (2010). Pengkajian Cerita Fiksi. Surakarta: Widya Sari.

Waluyo, H.J. (2011). Pengkajian dan Apresiasi Prosa Fiksi. Surakarta: UNS

Pres 